\title{
The influence of organizational culture on performance: Case study of the Moroccan ATM system
}

\author{
Ata Ghalem $^{1, *}$, Chafik Okar $^{2}$, Razane Chroqui ${ }^{2}$ and El Alami SEMMA ${ }^{1}$ \\ ${ }^{1}$ Laboratory IMII, Faculty of Sciences and Techniques, University Hassan 1st, Settat, Morocco \\ ${ }^{2}$ LAMSAD, Higher School of Technology, Berrechid, Morocco
}

\begin{abstract}
According to Ferreira and Otley (2009) contextual factors and organizational culture are considered as variable factors that have a significant impact on the performance management system framework, which comprises 12 questions/issues. The intention of this work is to define how organizational culture influences the question/issue of performance information use, through the example of Air Traffic Management (ATM). In fact, based on Schein's model we determine how two of the levels of organizational culture influence the performance information use within the Moroccan ATM system.
\end{abstract}

\section{Introduction}

Performance is a concept newly introduced to the aviation sector. Yet, it quickly became a requirement for the Air Navigation Service Providers (ANSP) organizations in order to improve and prosper in the future. However, most of the focus has been oriented towards the performance measurement, while overlooking the performance management. Many frameworks have been developed for the performance measurement systems, such as the balanced scorecard, the performance measurement matrix, the SMART pyramid and the performance prism. While, fewer frameworks were developed to study the performance management systems (PMS), which were mostly based on the management accounting and management control systems, such as the extended PMS framework of [1]. Some studies, which focused on the performance management systems, were interested in the elements that impact this system. Within the literature, some scholars admit the existence of a relationship between performance and organizational culture ([2]; [3]; [4]; [5]). In fact, [1] consider that culture is one of other factors that have an impact on control systems design and use, and considering that the extended framework is seen by the authors to be including all aspects of organizational control, culture accordingly has an impact on the PMS framework. Reference [1] argues that the consideration of the influencing factors on the PMS, of which culture is part, even if only implicitly, is a requirement in the study of the operations of the PMS.

This paper is organized through three sections. The first section discusses the PMS framework based on the work

Corresponding author: ata.ghalem@gmail.com of [1]. The second section presents the existing Air Traffic Management (ATM) performance frameworks, specifically the one proposed by the International Civil Aviation Organization (ICAO). The third section studies the influence of corporate culture on the performance of the Moroccan ATM system.

\section{Performance Management System framework}

Reference [6] proposed a framework for studying the operations of Management Control Systems (MCS) and completing the traditional framework suggested by [7]. Reference [6]'s framework focused on the management of organizational performance, and was structured around 5 issues that are believed to help developing a coherent structure for PMS and are represented as a set of questions:

1 Objectives: What are the key objectives that are central to the organization's overall future success, and how does it go about evaluating its achievement for each of these objectives?

2 Strategies and plans: What strategies and plans has the organization adopted and what are the processes and activities that it has decided will be required for it to successfully implement these? How does it assess and measure the performance of these activities?

3 Targets settings: What level of performance does the organization need to achieve in each of the areas defined in the above two questions) and how does it go about setting appropriate performance targets for them? 
4 Incentive rewards: What rewards will managers (and other employees) gain by achieving these performance targets (or, conversely, what penalties will they suffer by failing to achieve them)?

5 Information feedback loops: What are the information flows (feedback and feed-forward loops) that are necessary to enable the organization to learn from its experience) and to adapt its current behaviour in the light of that experience?

Later in 2009, [1] proposed an extension of these five questions as an extended framework named performance management systems framework. The authors specify that the naming of the framework, as 'performance management system', aims to reflect a shift from the traditional compartmentalized approaches to control in organizations to a broader perspective of the role of control in the managing of organizational performance.

The extended framework of the twelve questions proposed by [1] is represented as followed:

Q1. Vision and Mission: What is the vision and mission of the organization and how is this brought to the attention of managers and employees? What mechanisms, processes, and networks are used to convey the organization's overarching purposes and objectives to its members?

Q2. Key Success Factors: What are the key factors that are believed to be central to the organization's overall future success and how are they brought to the attention of managers and employees?

Q3. Organizational Structure: What is the organization structure and what impact does it have on the design and use of performance management systems (PMSs)? How does it influence and how is it influenced by the strategic management process?

Q4. Strategies and Plans: What strategies and plans has the organization adopted and what are the processes and activities that it has decided will be required for it to ensure its success? How are strategies and plans adapted, generated and communicated to managers and employees?

Q5. Key Performance Measures: What are the organization's key performance measures deriving from its objectives, key success factors, and strategies and plans? How these are specified and communicated and what role do they play in performance evaluation? Are there significant omissions?

Q6. Targets Setting: What level of performance does the organization need to achieve for each of its key performance measures (identified in the above question), how does it go about setting appropriate performance targets for them, and how challenging are those performance targets?

Q7. Performance Evaluation: What processes, if any, does the organization follow for evaluating individual, group, and organizational performance? Are performance evaluations primarily objective, subjective or mixed and how important are formal and informal information and controls in these processes?
Q8. Reward System: What rewards (financial and/or non-financial) will managers and other employees gain by achieving performance targets or other assessed aspects of performance (or, conversely, what penalties will they suffer by failing to achieve them)?

Q9. Information Flows, Systems and Networks: What specific information flows (feedback and feedforward), systems and networks has the organization in place to support the operation of its PMSs?

Q10. PMSs Use: What type of use is made of information and of the various control mechanisms in place? Can these uses be characterized in terms of various typologies in the literature? How do controls and their uses differ at different hierarchical levels?

Q11. PMSs Change: How have the PMSs altered in the light of the change dynamics of the organization and its environment? Have the changes in PMSs design or use been made in a proactive or reactive manner?

Q12. Strength and Coherence: How strong and coherent are the links between the components of PMSs and the ways in which they are used (as denoted by the above 11 questions)?

In fact, according to [1], the PMS is the wider context of MCS, as it is used to capture a holistic approach to the management and control of organizational performance. Thus, [1] define the PMS as the evolving formal and informal mechanisms, processes, systems, and networks used by organizations for conveying the key objectives and goals elicited by management, for assisting the strategic process and on-going management through analysis, planning, measurement, control, rewarding, and broadly managing performance, and for supporting and facilitating organizational learning and change.

Reference [1] points out that contextual factors and organizational culture are two aspects that permeate the PMSs and are not explicitly addressed by the twelve questions (see Fig 1 below). They add that contextual factors are shown by the literature to be influencing the control systems design and use, so their consideration is required even if they didn't include them in the framework. Those factors include: external environment, strategy, culture, organizational structure, size, technology, and ownership structure. [1] believe that strategy and organizational structure are already explicitly built into their framework and the remaining factors are considered as external influences, separating 'Culture' as a notable contextual variable as shown in Fig 1. Thus, the other contextual factors include: external environment, size, technology and ownership structure. The PMS framework was discussed in the study of [8] and [9], who developed a conceptual model of performance management systems (Alternative models of rationality) building on the work and insights of [6] and [10] and [1], to give a 'middle range' theoretical framework that can provide a language for analysing any PMS ([9]). 


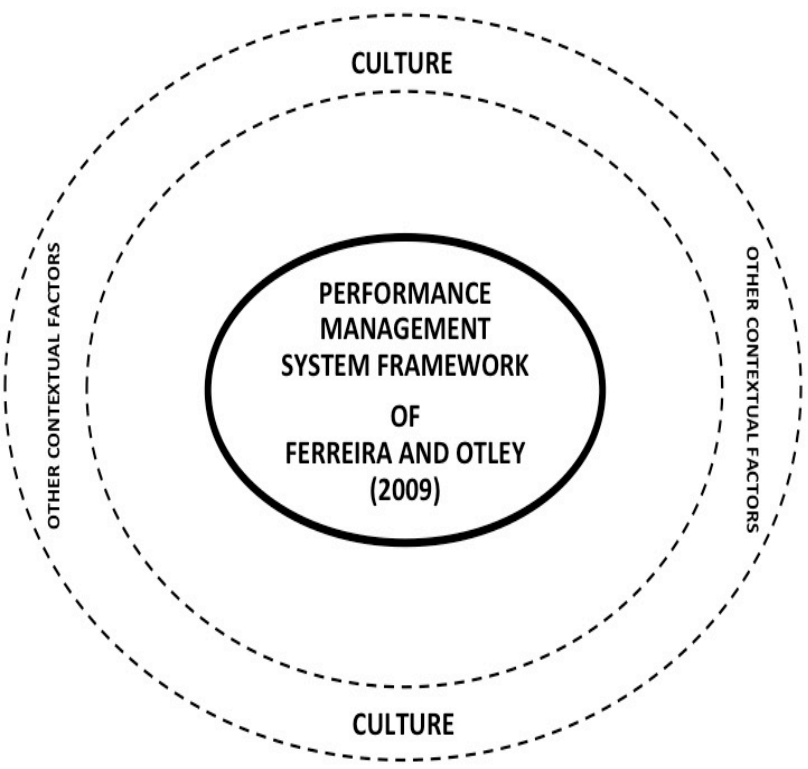

Fig 1. External influences on the PMS framework ([1])

References [8] and [9] consider that the first eight questions, which are related to the PMS design, would provide a conceptual nature of any PMS. Yet the remaining four questions, which are related to culture and context, will capture more underlying factors influencing the nature of the PMS. This creates a disagreement with [1]'s point of view, since they don't consider any longer these four questions as outlining cultural and contextual factors, as they initially did in 2005 ([10]). In fact, they put the contextual factors and culture outside the framework composed of all the twelve questions (bearing in mind that strategy and organizational structure are already explicitly built into the framework).

From both discussions above of [9] and [1], it is clear that the authors emphasis the importance of the influence of the contextual factors on the PMS. Reference [1] states that organizational culture is not explicitly discussed in their paper, they argue 'it is seen more as a contingent variable that may influence the PMS design rather than an organizational characteristic that can be manipulated... However, it is recognized that culture ... may be a highly influential feature of PMSs use' ([1]). Our mission is to study the influence of this organizational culture on the PMS through the case study of ATM; therefore, the next section discusses the performance frameworks that already exist the ATM sector.

\section{ATM performance frameworks}

ATM performance has known a great evolution in the last years, together with the evolution of the Air Navigation Systems. The International Civil Aviation Organization's (ICAO) performance framework has grown to be a Performance Based Global Air Navigation System with ASBU Methodology. The evolution started in the early 90's. Before 1992, the system was known as the Ground-based Air Navigation system. Then, in order to answer to the civil aviation growth, it evolved to be the Future Air Navigation Systems (FANS). Later in 1994, ICAO transitioned to the communications, navigation and surveillance/air traffic management (CNS/ATM) systems. In 2006, the system became mature enough to be considered as a Global ATM system. And then, in 2008, it was ready to be the Performance-based Global Air Navigation System. Since the civil aviation sector is always on continued and nonstopping roads of developments, the system was enhanced by the addition, in 2012, of the Aviation System Block Upgrade (ASBU) methodology.

ICAO has developed a Performance-Based Approach (PBA), which is a decision-making method for organizing the performance management process. This process is explained step-by-step in [11] in a set of six steps. The first step of the process defines the scope, the context and the general ambitions/expectations. These expectations of the ATM community [11] are categorized into 11 Key Performance Areas (KPAs): safety, security, environmental impact, cost effectiveness, capacity, flight efficiency, flexibility, predictability, access and equity, participation and collaboration, interoperability. The second step sets the objectives. The third step describes the quantification of these objectives, which should be SMART (Specific, Measurable, Achievable, Relevant and Time-bound). The forth step 4 is destined to the selection of solutions to exploit opportunities and resolve issues. The fifth step explains the implementation of solutions. The sixth step explains the assessment of achievement of objectives.

ICAO invited the member states and the regions to adopt the PBA methodology and the 11 KPAs. However, it recommended, as a starting point, to focus on a particular set of KPAs, or even a particular focus area within a KPA. Consequently, the EUR region adopted only 5 KPAs (safety, capacity, efficiency \& environment, cost-effectiveness and participation by the ATM community) ([12]), while the European Union (EU) focused on only 4 KPAs (safety, environment, capacity and cost-efficiency). In fact, the EU proposed its own framework that is the Single European Sky (SES) performance scheme ([13]). Moreover, other than the SES performance scheme other performance frameworks exist in Europe, such as: the Single European Sky ATM Research (SESAR) performance framework and EUROCONTROL's performance monitoring.

Morocco is member state of ICAO, a member of the EUR Region and is engaged with the EU by the agreement of 2006 and with EUROCONTROL by the agreement of 2016, which gives him the possibility of adopting any of the frameworks mentioned above. In fact, the performance measurement has only been introduced recently to the Moroccan ATM system. Firstly, following the steps of ICAO based on [11], secondly following the steps of EUR Region based on [12] and then considering the European Union framework described in [13] along with EUROCONTROL's performance monitoring. In other 
words, since 2015, the Air Navigation Pole (PNA) Which is the body of the Moroccan Airports Authority (ONDA) responsible for delivering Air Navigation Services in Morocco - adopted the same EUR Region approach and started with the subset of indicators in the five KPAs: Safety, Capacity, Efficiency and Environment, Cost-effectiveness and Participation by the ATM community. However, after the signature of the comprehensive agreement, in 2016, with EUROCONTROL, the ONDA/PNA altered its framework and adopted the one proposed by EUROCONTROL. This new agreement will help Morocco benefit from all the services and expertise offered by the agency, moreover, the framework will help the ONDA/PNA measure its performance and smooth the process of measurement. According to the interviews we had with the ONDA/PNA and based on the observations we made while being part of the organization, the management of performance is currently an on-going process that hasn't reached a maturity level yet. Today, the ONDA/PNA hasn't established, yet, a performance management system, instead it is focused on measuring its performance, based on the EUROCONTROL framework, in the four KPAs proposed by the EU, which are: Safety, Capacity, Environment and Cost-effectiveness. Note that, the ONDA/PNA is remarkably advanced in the measurement of its safety Key Performance Indicators (KPI) compared to capacity and environment KPIs, while it is still in the very first stage when it comes to the Cost-effectiveness KPA.

\section{Methodology}

Many studies were based on Schein's model such as [14]. According to Schein's model, there are three levels of organizational culture: artefacts, espoused values and beliefs and basic assumptions ([14]). So, in order to study the influence of culture on the PMS, which comprises twelve issues, we have to study the influence on each issue throughout the three different levels. However, the artefacts do not seem to have any type of influence on the PMS, thus this study will focus on the espoused values and some of the basic assumptions of the organization. On the other hand, due to the current state of the performance management process in the ONDA/PNA and in the absence of a complete PMS, it is difficult to study the influence of all the 12 questions of the framework of [1]. For this reason, instead of all the issues we will focus on Q10, which deals with the PMS's use since this aspect exist in the organization despite the absence of a mature PMS. In this case, the objective is to define how culture influences the use of information. Since the performance information received from the measurement system adopted by the ONDA/PNA is a very important decision-making aid.

\section{Influence of culture on performance}

In order to study the influence of culture on the PMS it is essential to define what does culture stand for. In the literature there are several definitions of corporate culture. Reference [4] chooses to use the definition of [15], they define culture as "a set of norms and values that are widely shared and strongly held throughout the organization". Reference [4] argues that this definition is the most suitable for their empirical study because the value component of culture is easier to measure. We believe that this definition presents, indeed, in a very precise way the direct meaning of corporate culture as shared values if the intention is to measure culture. However, in our case the intention is to study the influence of culture on the PMS. Thus, we need more meticulous definition that provides more aspects of culture. Reference [3] uses the definition of [16] who defines culture as "a pattern of basic assumptionsinvented, discovered, or developed by a given group as it learns to cope with its problems of external adaptation and internal integration - that has worked well enough to be considered ... the correct way to perceive, think, and feel in relation to those problems" [16]. According to [14], Schein's model presents three levels of organizational culture, the artefacts (the visible products or physical manifestations of an organization's culture), the espoused values and beliefs (or the documented norms, ideals, goals, and aspirations, of the organizational group), level 3: the basic underlying assumptions (the unconscious, taken-for-granted, and non-negotiable beliefs and values that influence how group members think, view, and feel about things and guide their behaviour).

According to the strategic plan of 2011-2016 of the ONDA/PNA the espoused values shared in the organisation are the following:

- Respect: Act with consideration, courtesy, honesty, listening and respect towards others.

- Team spirit: Work together for a collective success in all transparency and with a particular attention to the respect of the dignity and the personal life of the collaborators.

- Transparency: Avoid any form of opacity in our daily actions.

- Loyalty: Behave at all times towards ONDA in a loyal and diligent manner that protects its interests.

- Integrity: Behave honestly and fairly and treat your employees and partners equally.

- Responsibility: Perform our duties with loyalty, professionalism, effectiveness, efficiency and objectivity.

- Excellence: Always be part of the quest for performance and enjoy exemplary management.

On the other hand, one of the main basic assumptions of the ONDA/PNA is:

- Safety: safety of air traffic comes first regardless of any other condition.

Reference [2] argues that performance information use is defined as consistent when the desired behaviour is realized in the actual behaviour. The author mentions some of the uses of performance information: the three uses of [17]: (1) to coordinate; (2) to monitor; and (3) to diagnose; and the eight purposes of [18]: (1) to evaluate, 
(2) to control, (3) to budget, (4) to motivate, (5) to promote, (6) to celebrate, (7) to learn, and (8) to improve. Noting that that improvement is the main purpose of performance information.

Reference [2] states that the three levels of culture developed in Schein's model ([16]) influence the performance information. To show the impact of culture we suggest to consider the following hypothesizes. So hypothetically, in the Absence of respect, team spirit, transparency, loyalty, integrity, responsibility and excellence the information received from the measurement of performance will have one of the following possibilities: it will not exist or it will be incomplete in the lack of team spirit, it won't be correct in the lack of transparency, it won't follow its normal circuit between employees and top management in the lack of respect or it can even be late and not available when needed in the lack of responsibility. Through these hypothesises we can touch the aspects of impact on the information use. Moreover, safety of air traffic is the most basic and common assumption in all the ONDA/PNA. Every act, decision or suggestion is made based on the idea of safety. It is in itself a purpose of the whole performance measurement system adopted by the ONDA/PNA. According to EUROCONTROL Safety Culture is "the way safety is perceived, valued and prioritised in an organisation. It reflects the real commitment to safety at all levels in the organisation. Safety Culture is not something you get or buy; it is something an organisation has. Safety Culture can therefore be positive, negative or neutral. Its essence is in what people believe about the importance of safety, including what they think their peers, superiors and leaders really believe about safety's priority" [19]. If this culture is not taken into consideration when measuring performance a simple error in the indicators will give false information, which will lead to wrong decisions regarding the safety measures, consequently, the monitoring of performance, its evaluation, its improvement and our learning about it.

\section{Conclusions}

Through these hypothesizes we were able to visualize the important role of organizational culture in the ATM system, and the direct impact on the information use for instance, which can be easily manipulated by the different values and assumptions of the organization. However in order to generalize the results of the influence we believe that other ANSPs should be involved to test our hypothesis. The case study of Morocco isn't sufficient to study the influence of a vast concept such as culture, especially that, no two organizations use the same cultures. On the other hand, the immature performance management process of ONDA/PNA made it difficult to study the influence of culture on all the twelve issues of the PMS of [1]. With the possibility of studying the culture of different organizations we will be able to study only the mature issues of the PMS of every organization and combine the different results to obtain the final analysis of the impact of organizational culture on the twelve issues of the PMS. Moreover, this work focused on the influence of culture on performance, whilst the influence is plausible to be bidirectional or at least instead of an influencing effect other types of relationships might exist. Some researchers such as [20] argue about the existence of a relationship between both concepts, [20] state that 'here exists the problem of a dearth of research focusing exclusively on the effects of organizational culture on firm performance and more research is needed in understanding and exploring organizational cultureperformance relationship'. Therefore, future studies should be oriented to discuss the nature of the connection between culture and performance.

\section{References}

1. Ferreira, Aldónio, and David Otley. "The design and use of performance management systems: An extended framework for analysis." Management accounting research 20.4 (2009): 263-282.

2. Taylor, Jeannette. "Organizational culture and the paradox of performance management." Public Performance \& Management Review 38.1 (2014): 722.

3. Martinez, Elizabeth A., et al. "Organizational culture and performance." American Economic Review 105.5 (2015): 331-35.

4. Guiso, Luigi, Paola Sapienza, and Luigi Zingales. "The value of corporate culture." Journal of Financial Economics 117.1 (2015): 60-76.

5. Youngbantao, Unchan, and Nopadol Rompho. "The Uses of Measures in Performance Prism in Different Organizational Cultures." Journal of Accounting and Finance 15.6 (2015): 122.

6. Otley, David. "Performance management: a framework for management control systems research." Management accounting research 10.4 (1999): 363-382.

7. Anthony, R. N. "Planning and Control Systems: A Framework for Analysis, Cambridge, MA, Harvard University Graduate School of Business Administration." Studies in Management Control (1965).

8. Broadbent, Jane, and Richard Laughlin. "Performance management systems: a conceptual model and analysis of the development and intensification of 'new public management' in the UK." APIRA Conference, Auckland. 2007.

9. Broadbent, Jane, and Richard Laughlin. "Performance management systems: A conceptual model." Management Accounting Research 20.4 (2009): 283-295.

10. Ferreira, Aldónio, and David Otley. "The design and use of management control systems: an extended framework for analysis." AAA Management Accounting Section 2006 Meeting Paper (2005).

11. ICAO. "Manual on Global Performance of Air Navigation System (ICAO Doc 9883)." lst ed. (2009). 
12. ICAO. "EUR Region Performance Framework Document (ICAO EUR Doc 030) " (2013).

13. European Union. "COMMISSION IMPLEMENTING REGULATION (EU) N $\mathrm{N}^{\mathrm{o}}$ $390 / 2013$, laying down a performance scheme for air navigation services and network functions." Official Journal of the European Union L128 (2013): 1 .

14. Hogan, Suellen J., and Leonard V. Coote. "Organizational culture, innovation, and performance: A test of Schein's model." Journal of Business Research 67.8 (2014): 1609-1621.

15. O'Reilly, Charles A., and Jennifer A. Chatman. "Culture as social control: Corporations, cults, and commitment." In: B.M. Staw \& L.L. Cummings (Eds.), Research in Organizational Behavior, JAI Press 18 (1996): 157-200.

16. Schein, Edgar H. "Organizational Culture and Leadership." San Francisco: Jossey-Bass (1985).

17. Atkinson, Anthony A., John H. Waterhouse, and Robert B. Wells. "A stakeholder approach to strategic performance measurement." MIT Sloan Management Review 38.3 (1997): 25.

18. Behn, Robert D. "Why measure performance? Different purposes require different measures." Public administration review 63.5 (2003): 586-606.

19. EUROCONTROL. "Safety culture: an overview." (2008).

20. Mwaura, N. E., and H. Bula. "Organizational Culture and Firm Performance: A case of the Institute of Certified Public Accountants of Kenya." International Journal of Business, Social Sciences and Education (2017): 74-105. 